\title{
1q/19p co-polysomy predicts longer survival in patients with astrocytic gliomas
}

\author{
Wei Zeng ${ }^{1,3,4, *}$, Xiaohui Ren ${ }^{1,3,4, *}$, Yong Cui ${ }^{1,3,4}$, Haihui Jiang ${ }^{1,3,4}$, Xiuru Zhang ${ }^{2,3,4}$ and \\ Song Lin ${ }^{1,3,4}$ \\ ${ }^{1}$ Department of Neurosurgery, Beijing Tiantan Hospital, Capital Medical University, Beijing, China \\ ${ }^{2}$ Department of Pathology, Beijing Tiantan Hospital, Capital Medical University, Beijing, China \\ ${ }^{3}$ China National Clinical Research Center for Neurological Diseases, Beijing, China \\ ${ }^{4}$ Beijing Institute for Brain Disorders and Beijing Key Laboratory of Brain Tumor, Beijing, China \\ *These authors have contributed equally to this work \\ Correspondence to: Song Lin, email: linsong2005@126.com \\ Keywords: 1q/19p co-polysomy, single polysomy, astrocytic gliomas, overall survival, progression-free survival \\ Received: February 07, $2017 \quad$ Accepted: March 30, $2017 \quad$ Published: May 16, 2017 \\ Copyright: Zeng et al. This is an open-access article distributed under the terms of the Creative Commons Attribution License 3.0 \\ (CC BY 3.0), which permits unrestricted use, distribution, and reproduction in any medium, provided the original author and source \\ are credited.
}

\section{ABSTRACT}

Recently, we reported that 1q/19p co-polysomy predicted poor prognosis in oligodendroglial tumors. In this study, we aimed to retrospectively analyze the prognostic significance of $1 \mathrm{q} / \mathbf{1 9 p}$ polysomy in two large cohorts of astrocytic gliomas classified by the 2007 and 2016 WHO classification of tumors of the central nervous system. 1q/19p polysomy was detected using the FISH method, and factors that correlated with polysomy were analyzed by logistic regression. Survival analysis was used to identify independent prognostic factors correlated with survival. In the $\mathbf{W H O}_{2007}$ astrocytic glioma cohort $(\mathrm{N}=421)$, co-polysomy was associated with a younger age, whereas single polysomy was associated with higher tumor grades and a higher Ki-67 index $(P<0.05)$. Co-polysomy predicted longer survival, and single polysomy predicted shorter survival $(P<0.05)$. In multivariate analysis, co-polysomy maintained an independent prognostic impact on survival $(P=0.001)$ after adjustment for age, KPS, grade, removal degree, tumor size, Ki-67 index, and IDH1/2. In the WHO $_{2016}$ cohort $(\mathrm{N}=572)$, we validated the prognostic merit of co-polysomy after adjusting for related factors. In conclusion, 1q/19p co-polysomy added prognostic information in cases of astrocytic glioma and could be used for molecular stratification of this disease.

\section{INTRODUCTION}

Gliomas are the most common intracranial malignant tumor and often have a poor prognoses [1, 2]. Recently, molecular biomarkers including $1 \mathrm{p} / 19 \mathrm{q}$ co-deletion, BRAF mutation, IDH1/2 mutation, and TERT mutation have been widely used for glioma diagnosis, treatment, and prognosis prediction [3]. The $1 \mathrm{p} / 19 \mathrm{q}$ co-deletion is a unique genetic characteristic of oligodendroglial tumors $[4,5]$. This co-deletion predicts enhanced sensitivity to radiotherapy and chemotherapy and is included in the 2016 World Health Organization
(WHO) Classification of Tumors of the Central Nervous System [6]. In the detection of $1 p / 19 q$ deletions by fluorescence in situ hybridization (FISH), polysomy of $1 \mathrm{q}$ and $19 \mathrm{p}$ was frequently encountered, which indicated two or more $1 \mathrm{q} / 19 \mathrm{p}$ reference signals in the tumor nuclei. Some studies have found that $1 \mathrm{q} / 19 \mathrm{p}$ co-polysomy is associated with poor outcomes in oligodendrogliomas [7-10]. However, the frequency of $1 \mathrm{q} / 19 \mathrm{p}$ co-polysomy and its prognostic significance are still unknown in astrocytic tumors. Therefore, this study aimed to analyze the prognostic significance of $1 \mathrm{q} / 19 \mathrm{p}$ polysomy in the $\mathrm{WHO}_{2007}(\mathrm{~N}=421)$ and $\mathrm{WHO}_{2016}(\mathrm{~N}=572)$ classified cohorts, respectively. 


\section{RESULTS}

\section{Overall characteristics of the $\mathrm{WHO}_{2007}$ cohort}

The study cohort consisted of 421 patients with astrocytic glioma. The clinical and molecular details of all of the patients are summarized in Table 1. The patient ages ranged from 14 to 72 years with a mean of $43 \pm 13$ years. Two hundred fifty-three $(60.1 \%)$ were male, and 168 (39.9\%) were female. The median preoperative KPS score was 90 (IQR 10-90). Tumor sizes ranged from 1.2 to 11.0 $\mathrm{cm}$ with a mean size of $5.2 \pm 1.8 \mathrm{~cm}$. Two hundred seventyfive patients $(65.3 \%)$ received gross total resection (GTR) of the tumor, and 146 patients (34.7\%) received non-GTR resection. Two hundred sixty-seven patients $(63.4 \%)$ received postoperative chemotherapy, and 298 patients $(70.8 \%)$ received postoperative radiotherapy.

1q single polysomy was found in $18(4.3 \%)$ cases, $19 \mathrm{p}$ single polysomy in $40(9.5 \%)$ cases and $1 \mathrm{q} / 19 \mathrm{p}$ copolysomy in $85(20.2 \%)$ cases.

At the last follow-up, 243 of 405 patients $(60.0 \%)$ experienced tumor progression, and 164 of 413 patients (39.7\%) were dead. The median PFS and OS were 19.5 (95\% CI 15.7-23.3) months and 45.0 (95\% CI 33.6-56.4) months, respectively.

\section{Factors correlated with 1q/19p co-polysomy and single polysomy}

The factors associated with 1q/19p co-polysomy or single polysomy was analyzed by Chi-square test, including patient age, gender, tumor size, KPS score, resection degree, chemotherapy, radiotherapy, tumor grade, IDH1/2 mutation and Ki-67 proliferation index, as shown in Table 2.

Univariate analysis revealed that age $(P=0.001)$, and tumor grade $(P=0.036)$ were correlated with $1 \mathrm{q} / 19 \mathrm{p}$ co-polysomy. Logistic regression analysis confirmed age $\leq 40$ (OR 2.237, 95\%CI 1.381-3.623, $P=0.001$ ) as an independent factor correlated with $1 \mathrm{q} / 19 \mathrm{p}$ co-polysomy (Table 3).

Univariate analysis revealed that age $(P=0.041)$, tumor grade $(P=0.001)$ and Ki-67 $(P=0.002)$ were correlated with $1 \mathrm{q} / 19 \mathrm{p}$ single polysomy. Logistic regression analysis confirmed higher tumor grade (OR $1.740,95 \%$ CI $1.185-2.556, P=0.005)$ and Ki-67 $\geq 20 \%$ (OR 2.024, 95\%CI 1.062-3.857, $P=0.032$ ) as independent factors correlated with $1 \mathrm{q} / 19 \mathrm{p}$ single polysomy (Table 3 ).

\section{1q/19p co-polysomy predicts longer survival whereas single polysomy predicts shorter survival in astrocytic gliomas}

Of 421 patients, 85 harbored the 1q/19p co-polysomy, 58 harbored the $1 \mathrm{q} / 19 \mathrm{p}$ single polysomy, and 278 harbored no polysomy. Of the three subgroups, patients with $1 \mathrm{q} / 19 \mathrm{p}$ co-polysomy had the longest progression-free survival (PFS) and overall survival, patients with $1 \mathrm{q} / 19 \mathrm{p}$ single polysomy had the shortest PFS and OS, and patients without polysomy had intermediate PFS and OS (Figure $1 \mathrm{~A}$ and 1B). The median PFS of three subgroups were 65.0 months, 16.0 months and 12.0 months, respectively. The median OS of the three subgroups were N/A, 45.0 months and 21.5 months, respectively.

Patients with co-polysomy had longer PFS and OS than did those without co-polysomy (PFS: 65.0 months vs. 16.0 months, $P<0.001$; OS: N/A vs. 34.0 months, $P<0.001$, Supplementary Figure 1A and 1B).

Patients with single polysomy had shorter survival than did those without single polysomy (PFS: 12.0 months vs. 21.0 months, $P=0.001$; OS: 21.5 months vs. 51.0 months, $P<0.001$, Supplementary Figure $1 \mathrm{C}$ and 1D).

\section{1q/19p co-polysomy predicts longer survival in the $A, A A$ and GBM subgroups}

Subgroup analysis confirmed that $1 \mathrm{q} / 19 \mathrm{p}$ copolysomy predicted longer PFS and OS in the A, AA, and GBM subgroups. In the subgroup with astrocytomas (A, WHO grade II), the median PFS for patients with and without co-polysomy were N/A and 42.0 months $(P=0.013$, Supplementary Figure $2 \mathrm{~A})$, and the median OS were N/A and 65.5 months, respectively ( $P=0.047$, Supplementary Figure 2B). In the subgroup with anaplastic astrocytomas (AA, WHO grade III), the median PFS for patients with and without co-polysomy were 26.0 and 12.0 months $(P=0.018$, Supplementary Figure $2 C)$, and the median OS were N/A and 24.0 months, respectively $(P=0.008$, Supplementary Figure 2D). In the subgroup with glioblastoma (GBM, WHO grade IV), the median PFS for patients with and without co-polysomy was 14.0 and 10.0 months $(P=0.047$, Supplementary Figure $2 \mathrm{E})$, and the median OS were 32.0 and 18.5 months, respectively $(P=0.019$, Supplementary Figure $2 \mathrm{~F})$.

\section{1q/19p single polysomy predicts shorter survival in the GBM subgroup}

Subgroup analysis confirmed that $1 \mathrm{q} / 19 \mathrm{p}$ single polysomy predicted longer PFS and OS in the GBM subgroup but not in the A and AA subgroups due to limited cases. In the GBM subgroup, the median PFS for patients with and without single polysomy were 10.0 and 11.0 months ( $P=0.084$, Figure $2 \mathrm{~A}$ ). The median OS for patients with and without co-polysomy were 16.0 and 22.0 months $(P=0.027$, Figure 2B)

\section{Factors correlated with survival in astrocytic gliomas by log-rank analysis}

The prognostic factors associated with PFS and OS were analyzed by Kaplan-Meier survival analyses (Table 4). 
Table 1: Baseline characteristics for $\mathrm{WHO}_{2007} \operatorname{cohort}(\mathrm{N}=421)$

\begin{tabular}{|c|c|c|c|c|}
\hline \multirow{2}{*}{$\begin{array}{l}\text { Clinical } \\
\text { characteristics }\end{array}$} & \multicolumn{4}{|c|}{ No. of patients (\%) } \\
\hline & WHO II & WHO III & WHO IV & All \\
\hline \multicolumn{5}{|l|}{ Gender } \\
\hline Male & $95(59.7 \%)$ & $52(63.4 \%)$ & $106(58.9 \%)$ & $253(60.1 \%)$ \\
\hline Female & $64(40.3 \%)$ & $30(36.6 \%)$ & $74(41.1 \%)$ & $168(39.9 \%)$ \\
\hline \multicolumn{5}{|l|}{ Age (yrs) } \\
\hline Mean+SD & $39 \pm 11$ & $39 \pm 12$ & $50 \pm 12$ & $43 \pm 13$ \\
\hline Range & $16-64$ & $14-72$ & $14-71$ & $14-72$ \\
\hline \multicolumn{5}{|l|}{ Tumor size (cm) } \\
\hline Mean & $4.9 \pm 2.0$ & $5.5 \pm 1.9$ & $5.5 \pm 1.5$ & $5.2 \pm 1.8$ \\
\hline Range & $1.2-11.0$ & $2.0-10.0$ & $2.0-10.0$ & $1.2-11.0$ \\
\hline \multicolumn{5}{|l|}{ KPS score } \\
\hline Median & 90 & 90 & 80 & 90 \\
\hline Range & $50-90$ & $30-90$ & $10-90$ & $10-90$ \\
\hline N/A & 74 & 31 & 20 & 125 \\
\hline \multicolumn{5}{|l|}{ Resection } \\
\hline GTR & $91(57.2 \%)$ & $51(62.2 \%)$ & $133(73.9 \%)$ & $275(65.3 \%)$ \\
\hline Non-GTR & $68(42.8 \%)$ & $31(37.8 \%)$ & $47(26.1 \%)$ & $146(34.7 \%)$ \\
\hline \multicolumn{5}{|l|}{ Chemotherapy } \\
\hline Yes & $59(37.1 \%)$ & $56(68.3 \%)$ & $152(84.4 \%)$ & $267(63.4 \%)$ \\
\hline No & $87(54.7 \%)$ & $16(19.5 \%)$ & $21(11.7 \%)$ & $124(29.5 \%)$ \\
\hline N/A & $13(8.2 \%)$ & $10(12.2 \%)$ & $7(3.9 \%)$ & $30(7.1 \%)$ \\
\hline \multicolumn{5}{|l|}{ Radiotherapy } \\
\hline Yes & $77(48.4 \%)$ & $59(72.0 \%)$ & $162(90.0 \%)$ & $298(70.8 \%)$ \\
\hline No & $69(43.4 \%)$ & $12(14.6 \%)$ & $9(5.0 \%)$ & $90(21.4 \%)$ \\
\hline $\mathrm{N} / \mathrm{A}$ & $13(8.2 \%)$ & $11(13.4 \%)$ & $9(5.0 \%)$ & $33(7.8 \%)$ \\
\hline \multicolumn{5}{|l|}{ 1q/19p polysomy } \\
\hline 1q single polysomy & $5(3.1 \%)$ & $4(4.9 \%)$ & $9(5.0 \%)$ & $18(4.3 \%)$ \\
\hline 19 p single polysomy & $4(2.5 \%)$ & $9(10.9 \%)$ & $27(15.0 \%)$ & $40(9.5 \%)$ \\
\hline Co-polysomy & $33(20.8 \%)$ & $24(29.3 \%)$ & $28(15.6 \%)$ & $85(20.2 \%)$ \\
\hline No polysomy & $117(73.6 \%)$ & $45(54.9 \%)$ & $116(64.4 \%)$ & $278(66.0 \%)$ \\
\hline \multicolumn{5}{|l|}{ IDH1/2 mutation } \\
\hline Yes & $65(40.9 \%)$ & $30(36.6 \%)$ & $31(17.2 \%)$ & $126(29.9 \%)$ \\
\hline No & $53(33.3 \%)$ & $39(47.6 \%)$ & $111(61.7 \%)$ & $203(48.2 \%)$ \\
\hline $\mathrm{N} / \mathrm{A}$ & $41(25.8 \%)$ & $13(15.9 \%)$ & $38(21.1 \%)$ & $92(21.9 \%)$ \\
\hline \multicolumn{5}{|l|}{ Follow-up } \\
\hline Progression & $62 / 155(40.0 \%)$ & $44 / 77(57.1 \%)$ & $137 / 173(79.2 \%)$ & $243 / 405 *(60.0 \%)$ \\
\hline Mean PFS (mos) & $\begin{array}{c}48.0(95 \% \text { CI } 34.9- \\
61.1)\end{array}$ & $\begin{array}{c}21.0(95 \% \text { CI } 13.5- \\
28.6)\end{array}$ & $10.0(95 \%$ CI $8.5-11.5)$ & $\begin{array}{c}19.5(95 \% \text { CI } 15.7- \\
23.3)\end{array}$ \\
\hline Dead & $32 / 155(20.6 \%)$ & $29 / 78(37.2 \%)$ & $103 / 180(57.2 \%)$ & $164 / 413 *(39.7 \%)$ \\
\hline Mean OS (mos) & N/A & $\begin{array}{c}30.0(95 \% \text { CI } 20.2- \\
39.7)\end{array}$ & $\begin{array}{c}21.5(95 \% \text { CI } 17.5- \\
25.5)\end{array}$ & $\begin{array}{c}45.0(95 \% \text { CI } 33.6- \\
56.4)\end{array}$ \\
\hline
\end{tabular}

*PFS was not available in 16 cases and OS was not available in 8 cases. N/A= not available. GTR=gross-total resection. 
Table 2: clinical factors in association with polysomy in $\mathrm{WHO}_{2007}$ cohort $(\mathrm{N}=421)$

\begin{tabular}{|c|c|c|c|c|c|c|c|}
\hline \multirow{2}{*}{ Clinical factors } & & \multicolumn{2}{|c|}{ Frequency co-polysomy } & \multirow{2}{*}{$P$ value } & \multicolumn{2}{|c|}{ Frequency of single polysomy } & \multirow{2}{*}{$P$ value } \\
\hline & & Yes & No & & Yes & No & \\
\hline \multirow[t]{2}{*}{ Gender } & Male & $18.6 \%(47 / 253)$ & $81.4 \%(206 / 253)$ & 0.323 & $14.6 \%(37 / 253)$ & $\begin{array}{c}85.4 \% \\
(216 / 253)\end{array}$ & 0.567 \\
\hline & Female & $22.6 \%(38 / 168)$ & $77.4 \%(130 / 168)$ & & $12.5 \%(21 / 168)$ & $\begin{array}{c}87.5 \% \\
(147 / 168)\end{array}$ & \\
\hline \multirow[t]{2}{*}{ Age (yrs) } & $\leq 40$ & $28.4 \%(46 / 162)$ & $71.6 \%(116 / 162)$ & 0.001 & $9.3 \%(15 / 162)$ & $\begin{array}{c}90.7 \% \\
(147 / 162)\end{array}$ & 0.041 \\
\hline & $>40$ & $15.1 \%(39 / 259)$ & $84.9 \%(220 / 259)$ & & $\begin{array}{c}16.6 \% \\
(43 / 259)\end{array}$ & $\begin{array}{c}83.4 \% \\
(216 / 259)\end{array}$ & \\
\hline \multirow[t]{2}{*}{ Tumor size } & $\geq 6 \mathrm{~cm}$ & $18.5 \%(31 / 168)$ & $\begin{array}{c}81.5 \% \\
(137 / 168)\end{array}$ & 0.536 & $17.3 \%(29 / 168)$ & $\begin{array}{c}82.7 \% \\
(139 / 168)\end{array}$ & 0.112 \\
\hline & $<6 \mathrm{~cm}$ & $21.3 \%(54 / 253)$ & $\begin{array}{c}78.7 \% \\
(199 / 253)\end{array}$ & & $11.5 \%(29 / 253)$ & $\begin{array}{c}88.5 \% \\
(224 / 253)\end{array}$ & \\
\hline \multirow[t]{2}{*}{ KPS score* } & $\geq 70$ & $20.7 \%(49 / 237)$ & $\begin{array}{c}79.3 \% \\
(188 / 237)\end{array}$ & 0.858 & $\begin{array}{c}13.1 \% \\
(31 / 237)\end{array}$ & $\begin{array}{c}86.9 \% \\
(206 / 237)\end{array}$ & 0.527 \\
\hline & $<70$ & $22.0 \%(13 / 59)$ & $78.0 \%(46 / 59)$ & & $16.9 \%(10 / 59)$ & $83.1 \%(49 / 59)$ & \\
\hline \multirow[t]{2}{*}{ Resection degree } & GTR & $20.4 \%(56 / 275)$ & $\begin{array}{c}79.6 \% \\
(219 / 275)\end{array}$ & 0.903 & $\begin{array}{c}13.1 \% \\
(36 / 275)\end{array}$ & $\begin{array}{c}86.9 \% \\
(239 / 275)\end{array}$ & 0.656 \\
\hline & Non-GTR & $19.9 \%(29 / 146)$ & $\begin{array}{c}80.1 \% \\
(117 / 146)\end{array}$ & & $\begin{array}{c}15.1 \% \\
(22 / 146)\end{array}$ & $\begin{array}{c}84.9 \% \\
(124 / 146)\end{array}$ & \\
\hline \multirow[t]{2}{*}{ Chemotherapy } & Yes & $22.1 \%(59 / 267)$ & $\begin{array}{c}77.9 \% \\
(208 / 267)\end{array}$ & 0.135 & $\begin{array}{c}15.4 \% \\
(41 / 267)\end{array}$ & $\begin{array}{c}84.6 \% \\
(226 / 267)\end{array}$ & 0.053 \\
\hline & No & $15.3 \%(19 / 124)$ & $\begin{array}{c}84.7 \% \\
(105 / 124)\end{array}$ & & $8.1 \%(10 / 124)$ & $\begin{array}{c}91.9 \% \\
(114 / 124)\end{array}$ & \\
\hline \multirow[t]{2}{*}{ Radiotherapy* } & Yes & $20.5 \%(61 / 298)$ & $\begin{array}{c}79.5 \% \\
(237 / 298)\end{array}$ & 0.881 & $\begin{array}{c}15.1 \% \\
(45 / 298)\end{array}$ & $\begin{array}{c}84.9 \% \\
(253 / 298)\end{array}$ & 0.049 \\
\hline & No & $18.9 \%(17 / 90)$ & $81.1 \%(73 / 90)$ & & $6.7 \%(6 / 90)$ & $93.3 \%(84 / 90)$ & \\
\hline \multirow[t]{3}{*}{ Tumor grade } & WHO II & $20.8 \%(33 / 159)$ & $\begin{array}{c}79.2 \% \\
(126 / 159)\end{array}$ & 0.036 & $5.7 \%(9 / 159)$ & $\begin{array}{c}94.3 \% \\
(150 / 159)\end{array}$ & 0.001 \\
\hline & WHO III & $29.3 \%(24 / 82)$ & $70.7 \%(58 / 82)$ & & $15.9 \%(13 / 82)$ & $84.1 \%(69 / 82)$ & \\
\hline & WHO IV & $15.6 \%(28 / 180)$ & $\begin{array}{c}84.4 \% \\
(152 / 180)\end{array}$ & & $\begin{array}{c}20.0 \% \\
(36 / 180)\end{array}$ & $\begin{array}{c}80.0 \% \\
(144 / 180)\end{array}$ & \\
\hline \multirow[t]{2}{*}{ IDH1/2 mutation* } & Yes & $18.3 \%(23 / 126)$ & $\begin{array}{c}81.7 \% \\
(103 / 126)\end{array}$ & 0.224 & $\begin{array}{c}12.7 \% \\
(16 / 126)\end{array}$ & $\begin{array}{c}87.3 \% \\
(110 / 126)\end{array}$ & 0.378 \\
\hline & No & $13.3 \%(27 / 203)$ & $\begin{array}{c}86.7 \% \\
(176 / 203)\end{array}$ & & $\begin{array}{c}16.3 \% \\
(33 / 203)\end{array}$ & $\begin{array}{c}83.7 \% \\
(170 / 203)\end{array}$ & \\
\hline \multirow[t]{2}{*}{ Ki-67 index* } & $<20 \%$ & $20.7 \%(63 / 304)$ & $79.3 \%$ 241/304) & 0.646 & $\begin{array}{c}10.9 \% \\
(33 / 304)\end{array}$ & $\begin{array}{c}89.1 \% \\
(271 / 304)\end{array}$ & 0.002 \\
\hline & $\geq 20 \%$ & $18.1 \%(15 / 83)$ & $81.9 \%(68 / 83)$ & & $25.3 \%(21 / 83)$ & $74.7 \%(62 / 83)$ & \\
\hline
\end{tabular}

*KPS was available in 296 cases. Radiotherapy was available in 388 cases. IDH1/2 mutation was available in 329 cases. Ki-67 was available in 387 cases. GTR=gross-total resection. 
Table 3: Logistic regression of factors correlated with polysomy in $\mathrm{WHO}_{2007}$ cohort

\begin{tabular}{lcc}
\hline Clinical Factors & OR (95\% CI) & $P$ value \\
\hline Factors correlated with co-polysomy & & 0.001 \\
Age $\leq 40$ & $2.237(1.381-3.623)$ & $<0.001$ \\
constant & 0.177 & 0.005 \\
Factors correlated with single polysomy & & 0.032 \\
Higher tumor grade & $1.740(1.185-2.556)$ & $<0.001$ \\
Ki-67 $\geq 20 \%$ & $2.024(1.062-3.857)$ & 0.022 \\
constant & & \\
\hline
\end{tabular}
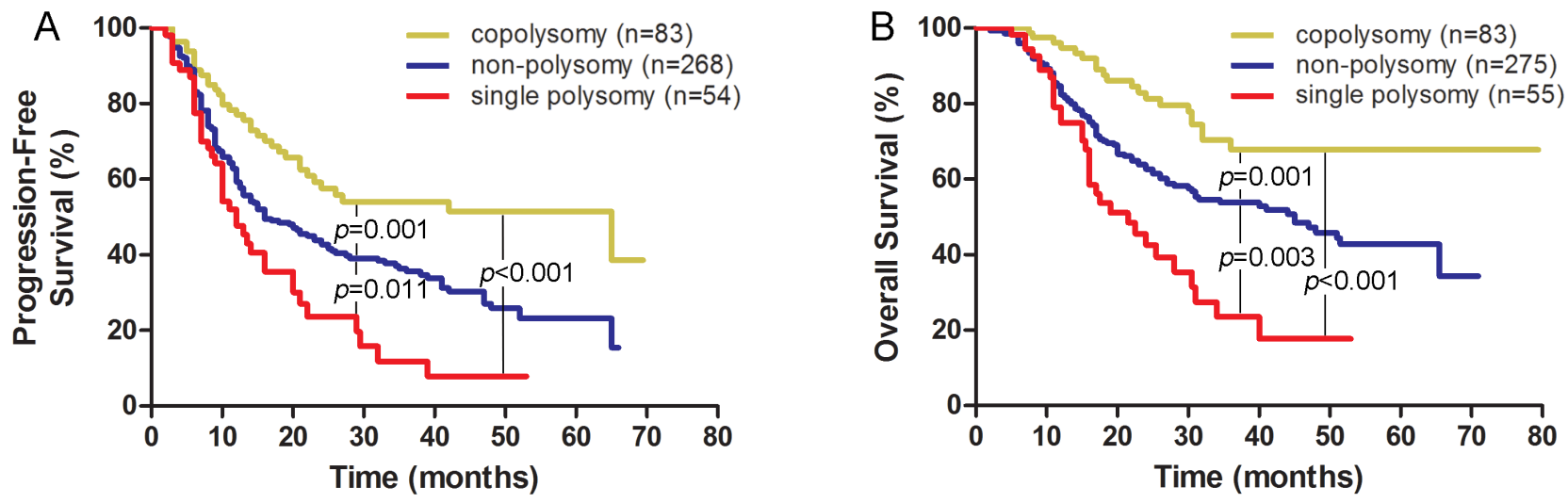

Figure 1: 1q/19p co-polysomy predicted longer survival, whereas single polysomy predicted shorter survival in the $\mathrm{WHO}_{2007}$ classified cohort (A for PFS and $\mathbf{B}$ for OS).
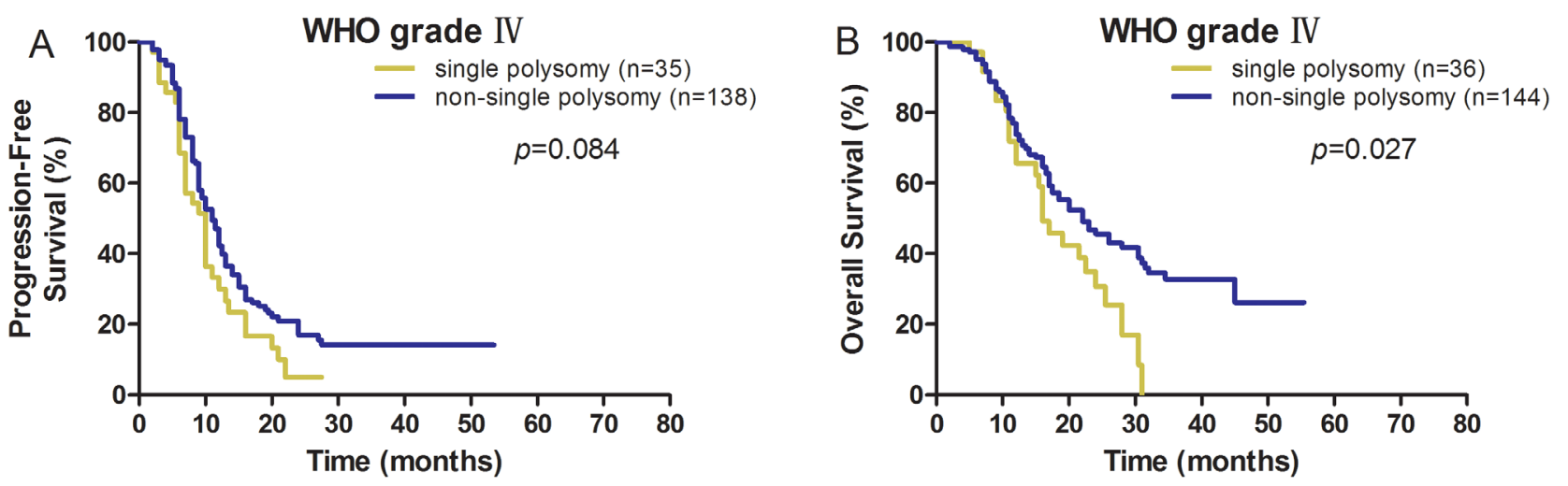

Figure 2: 1q/19p single polysomy predicted shorter survival in GBM (A for PFS and B for OS). 
Table 4: Log rank analysis of clinical factors correlated with survivals of the $\mathrm{WHO}_{2007}$ cohort

\begin{tabular}{|c|c|c|c|c|c|c|}
\hline Clinical factors & $\begin{array}{c}\text { Median PFS in } \\
\text { months }(95 \% \\
\text { CI) }\end{array}$ & $\begin{array}{c}\text { No. of } \\
\text { patients* }\end{array}$ & $P$ value & $\begin{array}{c}\text { Median OS in } \\
\text { months }(95 \% \mathrm{CI})\end{array}$ & $\begin{array}{c}\text { No. of } \\
\text { patients* }\end{array}$ & $P$ value \\
\hline \multicolumn{7}{|l|}{ Age (yrs) } \\
\hline$\leq 40$ & $41.0(28.0-54.0)$ & 157 & $<0.001$ & N/A & 159 & $<0.001$ \\
\hline$>40$ & $13.0(11.5-14.5)$ & 248 & & $27.0(21.3-32.7)$ & 254 & \\
\hline \multicolumn{7}{|l|}{ Gender } \\
\hline Male & $19.5(14.9-24.1)$ & 243 & 0.824 & $45.0(32.9-57.1)$ & 248 & 0.644 \\
\hline female & $20.0(13.8-26.0)$ & 162 & & $36.0(20.3-51.7)$ & 165 & \\
\hline \multicolumn{7}{|l|}{ KPS } \\
\hline$\geq 70$ & $21.0(15.8-26.2)$ & 229 & $<0.001$ & $\mathrm{~N} / \mathrm{A}$ & 232 & 0.006 \\
\hline$<70$ & $12.0(9.0-15.0)$ & 55 & & $24.0(14.7-33.3)$ & 58 & \\
\hline \multicolumn{7}{|l|}{ Removal degree } \\
\hline GTR & $20.0(12.0-22.0)$ & 268 & 0.034 & $\mathrm{~N} / \mathrm{A}$ & 272 & 0.001 \\
\hline Non-GTR & $17.0(13.8-26.1)$ & 137 & & $30.5(25.9-35.1)$ & 141 & \\
\hline \multicolumn{7}{|l|}{ Tumor size } \\
\hline$\geq 6 \mathrm{~cm}$ & $15.0(10.0-20.0)$ & 160 & 0.041 & $32.0(22.7-41.3)$ & 164 & 0.034 \\
\hline$<6 \mathrm{~cm}$ & $21.0(15.7-26.3)$ & 245 & & N/A & 249 & \\
\hline \multicolumn{7}{|l|}{ Ki-67 } \\
\hline$<20 \%$ & $23.0(18.2-27.8)$ & 296 & $<0.001$ & $\mathrm{~N} / \mathrm{A}$ & 299 & $<0.001$ \\
\hline$\geq 20 \%$ & $11.0(8.6-13.4)$ & 77 & & $22.0(16.1-27.9)$ & 81 & \\
\hline \multicolumn{7}{|l|}{ Tumor grade } \\
\hline WHO II & $48.0(34.9-61.1)$ & 155 & $<0.001$ & $\mathrm{~N} / \mathrm{A}$ & 155 & $<0.001$ \\
\hline WHO III & $21.0(13.3-28.6)$ & 77 & & $30.0(20.2-39.8)$ & 78 & \\
\hline WHO IV & $10.0(8.5-11.5)$ & 173 & & $21.5(17.5-25.5)$ & 180 & \\
\hline \multicolumn{7}{|l|}{$\begin{array}{l}1 \mathrm{q} / 19 \mathrm{p} \mathrm{co-} \\
\text { polysomy }\end{array}$} \\
\hline Yes & $65.0(11.2-118.8)$ & 83 & $<0.001$ & $\mathrm{~N} / \mathrm{A}$ & 83 & $<0.001$ \\
\hline No & $16.0(12.4-19.6)$ & 322 & & $34.0(24.2-43.8)$ & 330 & \\
\hline \multicolumn{7}{|l|}{ single polysomy } \\
\hline Yes & $12.0(9.1-14.9)$ & 54 & 0.001 & $21.5(13.9-29.1)$ & 55 & $<0.001$ \\
\hline No & $21.0(16.1-25.9)$ & 351 & & $51.0(37.1-64.9)$ & 358 & \\
\hline \multicolumn{7}{|l|}{ IDH1/2 mutation } \\
\hline Yes & $28.0(20.5-35.5)$ & 120 & 0.007 & $51.5(\mathrm{~N} / \mathrm{A})$ & 123 & 0.001 \\
\hline No & $18.0(13.3-22.7)$ & 195 & & $25.0(23.3-44.7)$ & 199 & \\
\hline
\end{tabular}

*PFS was not available in 16 cases and OS was no available in 8 cases. GTR=gross-total resection. 
Table 5: Cox regression model in association with prognoses in the $\mathrm{WHO}_{2007}$ cohort $(\mathrm{N}=421)$

\begin{tabular}{|c|c|c|c|c|}
\hline \multirow{2}{*}{ Factors } & \multicolumn{2}{|c|}{ PFS } & \multicolumn{2}{|c|}{ OS } \\
\hline & OR $(95 \% \mathrm{CI})$ & $P$ value & OR $(95 \% \mathrm{CI})$ & $P$ value \\
\hline $\begin{array}{l}\text { 1q/19p co-polysomy } \\
\text { (yes/no) }\end{array}$ & $0.538(0.374-0.772)$ & 0.001 & $0.460(0.287-0.738)$ & 0.001 \\
\hline Age $(\leq 40 />40)$ & $0.715(0.536-0.955)$ & 0.023 & $0.627(0.428-0.918)$ & 0.017 \\
\hline Tumor grade (IV/III/II) & $2.124(1.808-2.495)$ & $<0.001$ & $2.250(1.843-2.747)$ & $<0.001$ \\
\hline $\begin{array}{l}\text { Removal degree } \\
\text { (GTR/non-GTR) }\end{array}$ & $0.592(0.455-0.772)$ & $<0.001$ & $0.461(0.337-0.630)$ & $<0.001$ \\
\hline
\end{tabular}

$\mathrm{PFS}=$ progression-free survival; $\mathrm{OS}=$ overall survival; $\mathrm{OR}=$ odd ratio; $\mathrm{CI}=$ confidence interval. $\mathrm{GTR}=$ gross-total resection .

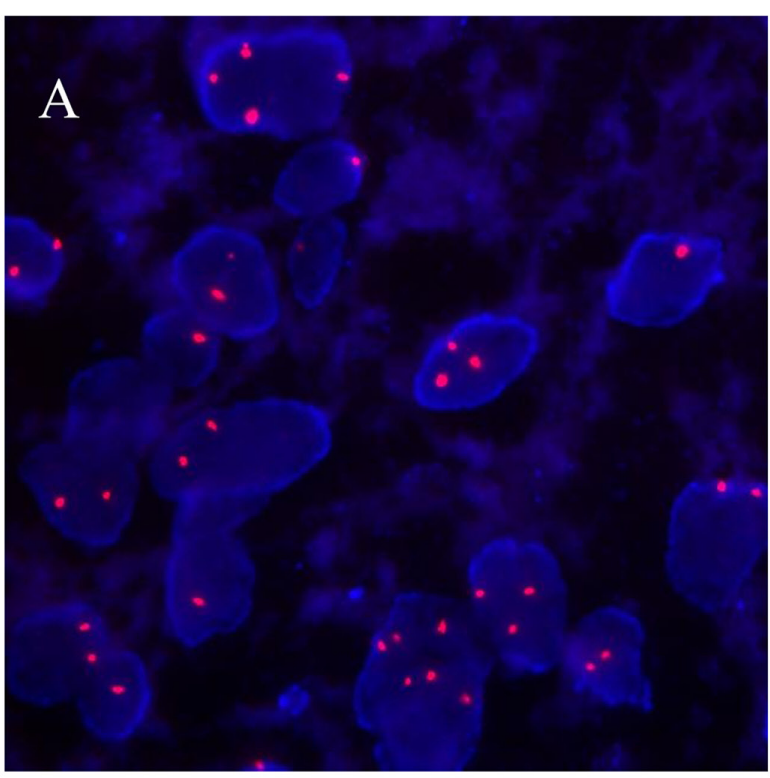

\section{B}
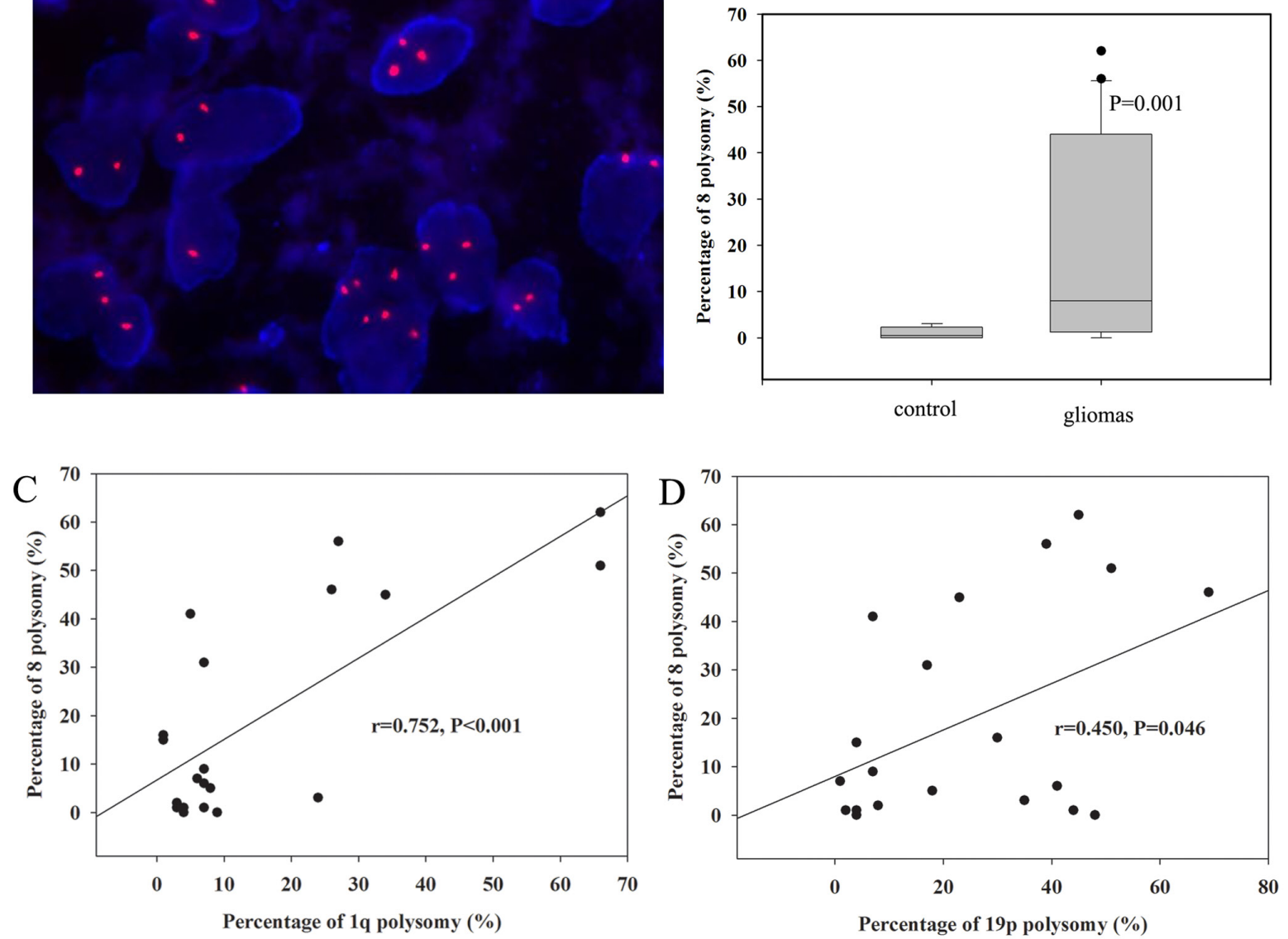

Figure 3: Chromosome 8 polysomy was shown in gliomas, including trisomy, tetrasomy and polysomy of more than 5 copies (A). The percentage of chromosome 8 polysomy in gliomas was higher than that in the control (B). The percentage of chromosome 8 polysomy was correlated with 1q polysomy (C) and 19p polysomy (D). 
Table 6: Cox regression model in association with prognoses in the $\mathrm{WHO}_{2016}$ cohort $(\mathrm{n}=572)$

\begin{tabular}{|c|c|c|c|c|}
\hline \multirow{2}{*}{ Factors } & \multicolumn{2}{|c|}{ PFS } & \multicolumn{2}{|c|}{ OS } \\
\hline & OR $(95 \%$ CI $)$ & $P$ value & OR $(95 \%$ CI $)$ & $P$ value \\
\hline $\begin{array}{l}\text { 1q/19p co-polysomy } \\
\text { (yes/no) }\end{array}$ & $0.503(0.322-0.785)$ & 0.003 & $0.557(0.318-0.976)$ & 0.041 \\
\hline Age $(\leq 40 />40)$ & $0.589(0.443-0.784)$ & $<0.001$ & $0.565(0.386-0.826)$ & 0.003 \\
\hline Tumor grade (IV/III/II) & $2.279(1.907-2.724)$ & $<0.001$ & $2.266(1.820-2.822)$ & $<0.001$ \\
\hline $\begin{array}{l}\text { Removal degree } \\
\text { (GTR/non-GTR) }\end{array}$ & $0.667(0.509-0.875)$ & 0.003 & $0.481(0.346-0.668)$ & $<0.001$ \\
\hline $\begin{array}{l}\text { IDH1/2 mutation (yes/ } \\
\text { no) }\end{array}$ & $0.782(0.580-1.055)$ & 0.107 & $0.638(0.440-0.924)$ & 0.018 \\
\hline
\end{tabular}

$\mathrm{PFS}=$ progression-free survival; $\mathrm{OS}=$ overall survival; $\mathrm{OR}=$ odd ratio; $\mathrm{CI}=$ confidence interval. $\mathrm{GTR}=$ gross-total resection.

According to the log-rank analysis, the clinical factors correlated with longer PFS included age $\leq 40(P<0.001)$, KPS $\geq 70(P<0.001)$, total resection of tumor $(P=0.034)$, tumor size $<6 \mathrm{~cm}(P=0.041)$, Ki-67 $<20 \%(P<0.001)$, lower tumor grade $(P<0.001), 1 \mathrm{q} / 19 \mathrm{p}$ co-polysomy $(P<0.001)$, no single polysomy $(P=0.001)$, and IDH1/2 mutation $(P=0.007)$, as shown in Table 4 . The factors correlated with longer OS included age $\leq 40(P<0.001)$, KPS $\geq 70$ ( $P=0.006)$, total resection of tumor $(P=0.001)$, tumor size $<6 \mathrm{~cm}(P=0.034), \mathrm{Ki}-67<20 \%(P<0.001)$, lower tumor grade $(P<0.001), 1 \mathrm{q} / 19 \mathrm{p}$ co-polysomy $(P<0.001)$, no single polysomy $(P<0.001)$, and IDH1/2 mutation $(P=0.001)$.

\section{1q/19p co-polysomy independently predicts longer survival in astrocytic gliomas by Cox regression}

Age, KPS, tumor resection degree, tumor size, Ki-67 index, tumor grade, 1q/19p co-polysomy, 1q/19p single polysomy, and IDH1/2 mutation were included in

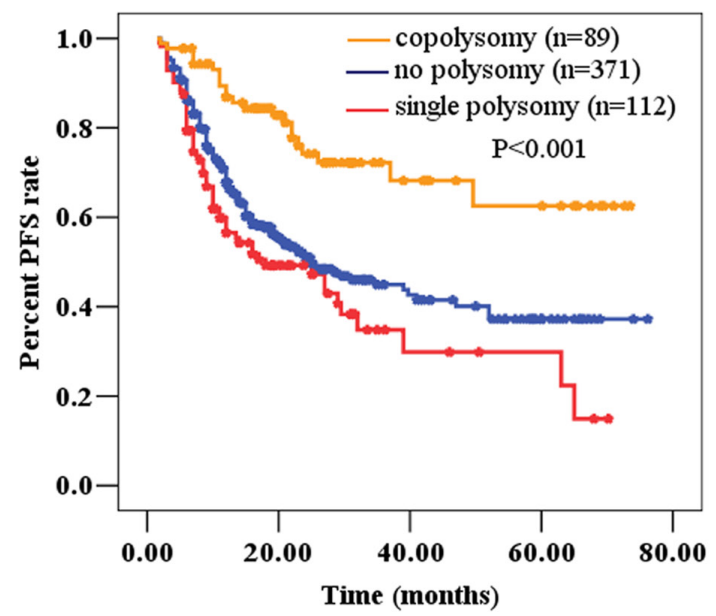

Cox regression analysis (Table 5). In the Cox regression model, the factors independently correlated with PFS were $1 \mathrm{q} / 19 \mathrm{p}$ co-polysomy (OR $0.538,95 \%$ CI [0.3740.772 ], $P=0.001$ ), age $\leq 40$ (OR $0.715,95 \%$ CI [0.536$0.955], P=0.023$ ), higher tumor grade (OR $2.124,95 \% \mathrm{CI}$ [1.808-2.495], $P<0.001)$, and gross-total resection of tumor (OR $0.592,95 \% \mathrm{CI}[0.455-0.772], P<0.001)$. The factors independently correlated with OS were $1 \mathrm{q} / 19 \mathrm{p}$ copolysomy (OR $0.460,95 \% \mathrm{CI}[0.287-0.738], P=0.001$ ), age $\leq 40$ (OR $0.627,95 \%$ CI [0.428-0.918], $P=0.017$ ), higher tumor grade (OR 2.250, 95\%CI [1.843-2.747], $P<0.001$ ), and gross-total resection of tumor (OR 0.461, 95\% CI [0.337-0.630], $P<0.001)$.

\section{Detection of chromosome 8 polysomy in gliomas}

To investigate the co-occurrence of polyploidy and polysomy, we investigated chromosome 8 polysomy in 20 glioma specimens by CEP8-FISH. Ten tumor cell-

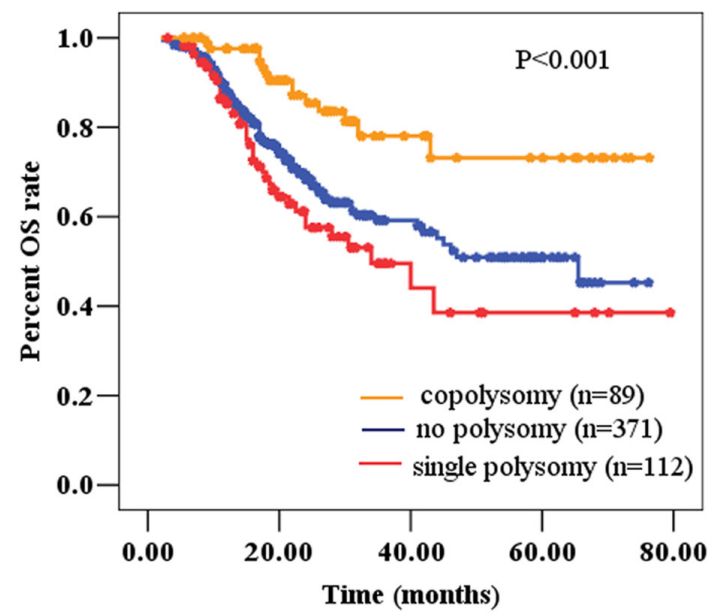

Figure 4: 1q/19p co-polysomy predicted longer survival, whereas single polysomy predicted shorter survival (A for PFS and B for OS) in the $\mathrm{WHO}_{2016}$ classified cohort. 
free surrounding tissues evidenced under pathological microscopy were selected from 10 patients as negative controls. Chromosome 8 polysomy could be found in gliomas, including trisomy, tetrasomy and polysomy of more than 5 copies (Figure 3A). The percentages of chromosome 8 polysomy in gliomas were higher than those in the negative control $(P=0.001$, Figure $3 \mathrm{~B})$. The percentage of chromosome 8 polysomy was correlated with 1q polysomy ( $\mathrm{r}=0.752, P<0.001$, Figure $3 \mathrm{C})$ and $19 \mathrm{p}$ polysomy $(\mathrm{r}=0.450, P=0.046$, Figure $3 \mathrm{D})$. The results showed that chromosome 8 polysomy co-existed with the $1 \mathrm{q} / 19$ p polysomy in these 20 glioma specimens, which indicated the polyploidy of the tumor.

\section{Validation using the $\mathrm{WHO}_{2016}$ classified cohort of astrocytic tumors}

To validate the independent survival impact of the $1 \mathrm{q} / 19 \mathrm{p}$ co-polysomy, we assessed the $\mathrm{WHO}_{2016}$ cohort $(\mathrm{N}=572$, Supplementary Table 1). In Cox regression models, we found that $1 \mathrm{q} / 19 \mathrm{p}$ co-polysomy was also an independent factor correlated with prognosis in astrocytic gliomas after controlling for age, grade, IDH1/2 mutation, and removal degree $(P<0.05$, Figure 4 and Table 6$)$.

\section{DISCUSSION}

According to the histological findings, gliomas can be divided into astrocytic, oligodendroglial, and mixed tumors. Compared with oligodendroglial and mixed tumors, astrocytic tumors exhibited worse prognoses. Recently, molecular biomarkers including the $1 \mathrm{p} / 19 \mathrm{q}$ co-deletion, BRAF mutation, IDH1/2 mutation, and TERT mutation have been widely used in the diagnosis, treatment, and prognostic prediction of gliomas. The $1 \mathrm{q} / 19 \mathrm{p}$ polysomy predicts unfavorable prognoses in the setting of $1 p / 19 q$ co-deleted oligodendroglial tumors (ODGs) [7-9]. In our previous study, we confirmed the prognostic merit of $1 \mathrm{q} / 19 \mathrm{p}$ co-polysomy in 148 1p/19q co-deleted ODGs [9]. However, the prognostic merit of $1 \mathrm{q} / 19 \mathrm{p}$ co-polysomy was unknown in astrocytic gliomas. Now, in the present study, we analyzed the prognostic merit of $1 \mathrm{q} / 19 \mathrm{p}$ co-polysomy in the $\mathrm{WHO}_{2007}$ and $\mathrm{WHO}_{2016}$ classified cohorts of astrocytic gliomas with longer follow-up periods.

So far, this is the first study to focus on $1 \mathrm{q} / 19 \mathrm{p}$ copolysomy in astrocytic tumors. For the first time, we found that $1 \mathrm{q} / 19 \mathrm{p}$ co-polysomy predicted longer survival in astrocytic tumors, irrespective of tumor grade. This finding was validated by the $\mathrm{WHO}_{2016}$ classified cohort. Geisenberger identified the 19 and 20 co-polysomy as a favorable prognostic marker in glioblastomas [11]. Previous studies regarding ploidy as a prognostic marker in gliomas were contradictory. Some studies found that the percentages of DNA aneuploidy in gliomas correlated with tumor grade and shorter survival [12-16], whereas others found no association [17-19], and still others reported associations with longer survival [20-22]. El-Rayes et al. implied that cellular DNA content parameters may correlate with the natural history and treatment outcomes of newly diagnosed untreated patients with astrocytomas [23].

\section{A. Polysomy (+)}
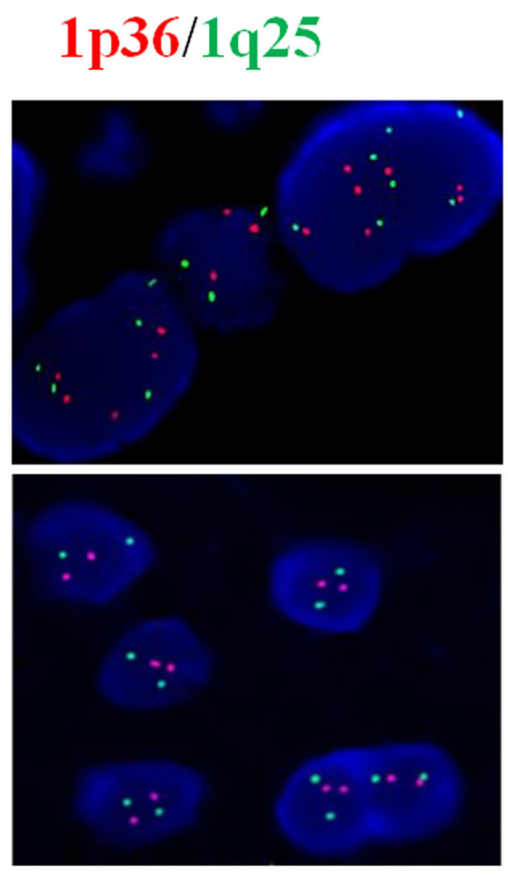

$19 \mathrm{q} 13 / 19 \mathrm{p} 13$
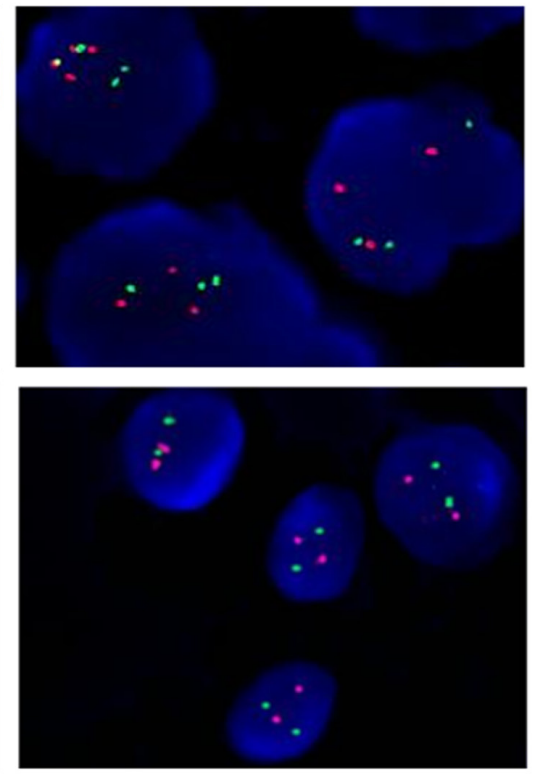

Figure 5: Astrocytic tumor with 1q/19p co-polysomy (A) and without polysomy (B) by FISH detection. The red signal represents the 1 p36 and 19q13 FISH probes, whereas the green signal represents the 1q25 and 19p13 FISH probes. 
The prognostic merit of co-polysomy in astrocytic tumors was opposite to that in oligodendroglial tumors. This may explain why previous studies about ploidy as a prognostic marker in gliomas were contradictory. To clarify the prognostic merit of polyploidy or polysomy in gliomas, detailed stratification is necessary. In this study, $1 q / 19 p$ co-polysomy predicted longer survival, whereas single polysomy predicted shorter survival in astrocytic tumors. In oligodendroglial tumors, however, patients with co-polysomy had worse prognoses regardless of tumor grade, especially in the $1 \mathrm{p} / 19 \mathrm{q}$ co-deleted subgroups [7-10]. Perhaps this could be explained by the theory of the aneuploidy paradox [24]. The beneficial effects of aneuploidy in enhancing cell growth will be most evident under stringent selective pressures and induce a "mutator phenotype" that increases DNA damage and genomic instability [24].

To clarify the relationship between polyploidy and polysomy in gliomas, we assessed the frequency of chromosome 8 polysomy in gliomas. We found that chromosome 8 polysomy was correlated with 1q polysomy and $19 \mathrm{p}$ polysomy. The correlation of two independent polysomy implied tumor polyploidy [25].

To further identify the mechanism between copolysomy and favorable prognoses, we analyzed the factors correlated with co-polysomy. Age $\leq 40$ was correlated with $1 \mathrm{q} / 19 \mathrm{p}$ co-polysomy as an independent factor. Ki-67 was not correlated with co-polysomy in astrocytic tumors. 1q/19p co-polysomy correlated with younger age, which was consistent with the results of Andrea L's report [8]. It was also reported that younger patients were strongly correlated with longer overall survivals in gliomas [19, 20, 26, 27]. In addition, Perry reported that aneuploidy in anaplastic astrocytic tumors was associated with younger age and longer survival, whereas diploidy was associated with older age and shorter survival [20]. It was also speculated that radiotherapeutic and chemotherapeutic treatments may be more effective in aneuploid tumors and account for improved survival [20].

For the first time, we reported that the $1 \mathrm{q} / 19 \mathrm{p}$ single polysomy predicted the shortest survival in astrocytic gliomas, although it was not confirmed as an independent factor in Cox regression. The median PFS and OS were 12.0 months and 21.5 months, respectively, in the $\mathrm{WHO}_{2007}$ classified cohort. Subgroup analysis confirmed this trend in GBM. This finding was also validated by the $\mathrm{WHO}_{2016}$ classified cohort. To further identify the mechanism between single polysomy and unfavorable prognoses, we analyzed the factors correlated with single polysomy. Higher tumor grade and $\mathrm{Ki}-67 \geq 20 \%$ were independent factors correlated with single polysomy. It was speculated that single polysomy was associated with greater malignancy and proliferative activity.

\section{Study limitations}

The greatest limitation of this study is the lack of validation of polysomy by other methods. For the first time, Snuderl et al. provided the definition of polysomy of 1 and 19 based on the FISH by-product result in the detection of $1 \mathrm{p} / 19 \mathrm{q}$ co-deletion [7]. Strictly speaking, polysomy is a copy number gain of an entire body of a specific chromosome. An increased number of probe signals indicated local amplification of the locus targeted by FISH probes. These results were not validated using other methods, such as array CGH or MLPA.

This is a retrospective study involving cases from 2009 to 2016, and biomarkers such as MGMT, TERT, ATRX, and H3K27 were not available for all cases and were not analyzed in this article. In addition, many tumors showed high variability in copy number, which precluded our further sub-stratification on the copy number.

In conclusion, we reported the prognostic significance of the $1 \mathrm{q} / 19 \mathrm{p}$ polysomy in astrocytic tumors. $1 \mathrm{q} / 19 \mathrm{p}$ co-polysomy independently predicted longer survival after adjusting for the commonly applied standard prognostic markers. Therefore, it could be useful in the molecular stratification of gliomas.

\section{MATERIALS AND METHODS}

\section{Ethics statement}

A $\mathrm{WHO}_{2007}$ classified cohort of patients $(\mathrm{N}=421)$ with astrocytic glioma was enrolled in the study. A $\mathrm{WHO}_{2016}$ cohort $(\mathrm{N}=572)$ with astrocytic gliomas was used as a validated cohort. All patients provided written informed consent for the current study, and the clinical study was approved by the Medical Ethics Committee of Capital Medical University.

\section{Pathological examination}

For the $\mathrm{WHO}_{2007}$ classified cohort $(\mathrm{N}=421)$, all specimens were independently reviewed and graded by two senior neuropathologists according to the 2007 WHO Classification of Tumors of the Central Nervous System [28]. For the $\mathrm{WHO}_{2016}$ cohort $(\mathrm{N}=572)$, assessments were made according to the 2016 WHO Classification of Tumors of the Central Nervous System [6]. The histological diagnoses of the tumor specimens were reviewed and confirmed by a third senior neuropathologist. If the first two pathologists did not agree on the diagnosis, a third senior neuropathologist would resolve the judgment. If the three neuropathologists could not reach an agreement, the case was submitted to the pathological committee of Beijing Neurosurgical Institute and Beijing Tiantan Hospital for final diagnosis. 


\section{Recording of clinical material}

The clinical, radiological, operative, and pathological records were recorded. All of the patients were closely followed including records of adjuvant therapies, neuro-imaging, PFS and OS. Tumor size was defined as the maximal diameter of the tumor in the axial, sagittal or coronary planes on enhanced $\mathrm{T} 1$ images for high-grade gliomas and on T2/Flair images for low-grade gliomas. Tumor resection degree was defined according to the reported criteria [29-31]. The PFS was defined as the duration from the date of surgery to the date of recurrence as demonstrated by radiology. The OS was defined as the duration from the date of surgery to the date of death. The KPS score was used to judge preoperative functional status. Peri-operative death, which was defined as death within 30 days of surgery, was excluded from this study.

\section{Detection of the $1 p / 19 q$ co-deletion and $1 q / 19 p$ polysomy by FISH method}

The 1p/19q fluorescent probe kit (Vysis, USA) was used for the FISH test as was described previously [9, 32]. The assessment and interpretation of FISH results were performed according to guidelines defined by the SIOP Europe Neuroblastoma Pathology and Biology and Bone Marrow Group [33]. Tumors with more than 30\% of nuclei showing DNA loss were defined as tumors with chromosomal loss. The tumor was considered to have a 1q and $19 \mathrm{p}$ polysomy if $30 \%$ of nuclei showed more than two 1q or 19p deletions [7] (Figure 5). All cases with 1p/19q co-deletions were excluded.

\section{Quality control for FISH detection of $1 p / 19 q$ co- deletion and polysomy}

For each case, a paraffin-embedded tumor block was selected based on tumor content, including the highest grade component and representation of the predominant morphology of the individual case. Several sections were prepared for FISH. The first and last sections were hematoxylin and eosin stained, and regions representing tumor were delineated. The first section was examined to ensure that it met the standards by which the block was selected. For FISH analysis, the section immediately adjacent to the first hematoxylin and eosin stained slide was used to minimize the effects of tumor heterogeneity. In the corresponding region rich in tumor cells, more than 100 non-overlapping nuclei were enumerated per hybridization for each probe. Some parameters were used for quality control as reported previously [9].

\section{IDH1/2 sequence analysis}

Genomic DNA was isolated from snap-frozen tissues using the QIAmp DNA mini-kit, as instructed by the manufacturer (Qiagen). A fragment $254 \mathrm{bp}$ in length spanning the catalytic domain of IDH1 and including codon 132 was amplified using the sense primer IDH1 F: 5'-ACCAAATGGCACCATACG-3' and the antisense primer IDH1 R: 5'-TTCATACCTTGCTTAATGGGG-3'. A fragment $293 \mathrm{bp}$ in length spanning the catalytic domain of IDH2 and including codon 172 was amplified using the sense primer IDH2 F: 5'-GCTGCAGTGGGACCACTATT-3' and the antisense primer IDH2 R: 5'-TGTGGCCTTGTACTGCAGAG'. PCR using standard buffer conditions, 30 ng of DNA and GoTaq DNA Polymerase (TaKaRa, Japan) employed 35 cycles with denaturing at $95^{\circ} \mathrm{C}$ for $30 \mathrm{~s}$, annealing at $54^{\circ} \mathrm{C}$ for $45 \mathrm{~s}$ and extension at $72^{\circ} \mathrm{C}$ for $50 \mathrm{~s}$ in a total volume of $25 \mu \mathrm{L}$. The PCR amplification product was then sequenced for analysis.

\section{Assessment of chromosome 8 polysomy in glioma specimens by FISH}

Chromosome 8 polysomy was detected in 20 patient tumor specimens by FISH, and tumor cellfree surrounding tissues evidenced under pathologic microscopy were selected from 10 patients as negative controls. The Vysis CEP8 SpectrumOrange Direct Labeled Fluorescent DNA Probe kit was used for FISH testing. Paraffin slides ( $4 \mu \mathrm{m}$ thick) were deparaffinized, dehydrated, and incubated in $1 \mathrm{~mol} / \mathrm{L} \mathrm{NaSCN}$ for $35 \mathrm{~min}$ at $80^{\circ} \mathrm{C}$. The slides were then immersed in pepsin solution $(0.65 \%$ in protease buffer with $0.01 \mathrm{~mol} / \mathrm{L} \mathrm{HCl})$ for 10 min at $37^{\circ} \mathrm{C}$, and the tissues were fixed in $10 \%$ neutral buffered formalin. The specimens were then dehydrated in ethanol (70, 85, and $100 \%, 2 \mathrm{~min}$ in each bath) and air-dried. Twenty microliters of each probe was then added separately, and the slides were sealed with rubber cement. After co-denaturation for $10 \mathrm{~min}$ at $75^{\circ} \mathrm{C}$, the slides were then placed in a humidified atmosphere with Hybrite (ThermoBriteTM vysis) for $16 \mathrm{~h}$ at $37^{\circ} \mathrm{C}$. The slides were then immersed in $2 \mathrm{x} \mathrm{SSC} / 0.3 \% \mathrm{NP}-40$ for 2 $\mathrm{min}$ at RT and then in $2 \mathrm{xSSC} / 0.3 \% \mathrm{NP}-40$ for $2 \mathrm{~min}$ at $73^{\circ} \mathrm{C}$. After drying, the nuclei were counterstained with 4,6-diamidino2-phenylindole (DAPI) and an antifade compound (p-Phenylenediamine). FISH signals for each locus-specific FISH probe were assessed using an Olympus BX51TRF microscope (Olympus, Inashi, Nagano, Japan) equipped with a triple-pass filter (DAPI/Green/ Orange; Vysis). The entire areas of the tissue microarray cores were evaluated in each case, and as many non-overlapping nuclei as possible $(\geq 100$ per hybridization) were assessed for red (target) signals.

\section{Statistics}

Summary data are presented as the mean \pm SD for parametric data and as the median with the IQR in parentheses for nonparametric data. For intergroup comparisons, Student's t-test was used for parametric 
data and the Mann-Whitney U-test for nonparametric data. Percentages were compared using the chi-square test or Fisher's exact test where appropriate. Survival as a function of time was plotted using the Kaplan-Meier method, and the log-rank analysis was used to compare Kaplan-Meier plots. Multivariate proportional hazards regression analysis was used to identify factors associated with PFS and OS. In this analysis, all variables associated with survival in univariate analysis $(P<0.05)$ were included in a step-wise multivariate proportional hazards regression model. SPSS 13.0 (SPSS for Windows, version 13.0 [SPSS Inc., Chicago, Illinois, USA]) was used for statistical analysis. Probability values were obtained using 2-sided tests with statistical significance defined as $P<0.05$.

\section{Abbreviations}

$\mathrm{WHO}=$ World Health Organization; FISH=fluorescence in situ hybridization; GTR=gross total resection; $\mathrm{A}=$ astrocytoma; $\mathrm{AA}=$ anaplastic astrocytoma; $\mathrm{GBM}=$ glioblastoma; $\quad \mathrm{PFS}=$ progression-free survival; $\mathrm{OS}=$ overall survival.

\section{Author contributions}

Author contributions to the study and manuscript preparation include the following. Conception and design: Zeng, Ren, Lin. Acquisition of data: Zeng, Ren, Cui, Jiang, Zhang, Lin. Analysis and interpretation of data: Zeng, Ren. Drafting the article: Zeng, Ren. Critically revising the article: Zeng, Ren, Lin. Reviewed submitted version of manuscript: all authors. Approved the final version of the manuscript on behalf of all authors: Lin. Statistical analysis: Zeng, Ren. Administrative/technical/material support: Lin. Study supervision: Lin.

\section{ACKNOWLEDGMENTS}

We acknowledge financial support by the National Natural Science Foundation of China (81401381\&81571632), the Capital Health Research and Development of Special (2014-2-2042) and the Chinese Society of Neuro-oncology (CSNO-2014-MSD04).

\section{CONFLICTS OF INTEREST}

The authors report no conflicts of interest concerning the material or methods used in this study or the findings specified in this paper.

\section{FUNDING}

This work was supported by the National Natural Science Foundation of China (81401381\&81571632) and the Capital Health Research and Development of Special of Beijing (2014-2-2042).

\section{REFERENCES}

1. Omuro A, DeAngelis LM. Glioblastoma and other malignant gliomas: a clinical review. JAMA. 2013; 310:1842-1850.

2. Schwartzbaum JA, Fisher JL, Aldape KD, Wrensch M. Epidemiology and molecular pathology of glioma. Nat Clin Pract Neurol. 2006; 2:494-503, 1-516.

3. Eckel-Passow JE, Lachance DH, Molinaro AM, Walsh KM, Decker PA, Sicotte H, Pekmezci M, Rice T, Kosel ML, Smirnov IV, Sarkar G, Caron AA, Kollmeyer TM, et al. Glioma Groups Based on 1p/19q, IDH, and TERT Promoter Mutations in Tumors. N Engl J Med. 2015; 372:2499-508.

4. Cairncross G, Berkey B, Shaw E, Jenkins R, Scheithauer B, Brachman D, Buckner J, Fink K, Souhami L, Laperierre N, Mehta M, Curran W, and Intergroup Radiation Therapy Oncology Group Trial 9402. Phase III trial of chemotherapy plus radiotherapy compared with radiotherapy alone for pure and mixed anaplastic oligodendroglioma: Intergroup Radiation Therapy Oncology Group Trial 9402. J Clin Oncol. 2006; 24:2707-14.

5. Kraus JA, Koopmann J, Kaskel P, Maintz D, Brandner S, Schramm J, Louis DN, Wiestler OD, von Deimling A. Shared allelic losses on chromosomes $1 p$ and $19 q$ suggest a common origin of oligodendroglioma and oligoastrocytoma. J Neuropathol Exp Neurol. 1995; 54:91-95.

6. Louis DN, Perry A, Reifenberger G, von Deimling A, Figarella-Branger D, Cavenee WK, Ohgaki H, Wiestler OD, Kleihues P, Ellison DW. The 2016 World Health Organization Classification of Tumors of the Central Nervous System: a summary. Acta Neuropathol. 2016; 131:803-20.

7. Snuderl M, Eichler AF, Ligon KL, Vu QU, Silver M, Betensky RA, Ligon AH, Wen PY, Louis DN, Iafrate AJ. Polysomy for chromosomes 1 and 19 predicts earlier recurrence in anaplastic oligodendrogliomas with concurrent 1p/19q loss. Clin Cancer Res. 2009; 15:6430-37.

8. Wiens AL, Cheng L, Bertsch EC, Johnson KA, Zhang S, Hattab EM. Polysomy of chromosomes 1 and/or 19 is common and associated with less favorable clinical outcome in oligodendrogliomas: fluorescent in situ hybridization analysis of 84 consecutive cases. J Neuropathol Exp Neurol. 2012; 71:618-624.

9. Ren X, Jiang H, Cui X, Cui Y, Ma J, Jiang Z, Sui D, Lin S. Co-polysomy of chromosome 1q and 19p predicts worse prognosis in $1 \mathrm{p} / 19 \mathrm{q}$ codeleted oligodendroglial tumors: FISH analysis of 148 consecutive cases. Neuro-oncol. 2013; 15:1244-50.

10. Jiang H, Ren X, Zhang Z, Zeng W, Wang J, Lin S. Polysomy of chromosomes 1 and 19: an underestimated 
prognostic factor in oligodendroglial tumors. J Neurooncol. 2014; 120:131-138.

11. Geisenberger C, Mock A, Warta R, Rapp C, Schwager C, Korshunov A, Nied AK, Capper D, Brors B, Jungk C, Jones D, Collins VP, Ichimura K, et al. Molecular profiling of long-term survivors identifies a subgroup of glioblastoma characterized by chromosome 19/20 co-gain. Acta Neuropathol. 2015; 130:419-34.

12. Cho KG, Nagashima T, Barnwell S, Hoshino T. Flow cytometric determination of modal DNA population in relation to proliferative potential of human intracranial neoplasms. J Neurosurg. 1988; 69:588-92.

13. Coons SW, Johnson PC, Pearl DK. Prognostic significance of flow cytometry deoxyribonucleic acid analysis of human astrocytomas. Neurosurgery. 1994; 35:119-25; discussion 125-6.

14. Danova M, Giaretti W, Merlo F, Mazzini G, Gaetani P, Geido E, Gentile S, Butti G, Di Vinci A, Riccardi A. Prognostic significance of nuclear DNA content in human neuroepithelial tumors. Int J Cancer. 1991; 48:663-67.

15. Nishizaki T, Orita $T$, Furutani $Y$, Ikeyama $Y$, Aoki H, Sasaki K. Flow-cytometric DNA analysis and immunohistochemical measurement of Ki-67 and BUdR labeling indices in human brain tumors. J Neurosurg. 1989; 70:379-84.

16. Vavruch L, Nordenskjöld B, Carstensen J, Eneström S. Prognostic value of flow cytometry and correlation to some conventional prognostic factors: a retrospective study of archival specimens of 134 astrocytomas. J Neurosurg. 1996; 85:146-51.

17. Gasińska A, Krzyszk wski T, Niemiec J, Adamczyk A, Skołyszewski J. Prognostic significance of DNA ploidy and proliferation rate in human astrocytic gliomas. Folia Histochem Cytobiol. 2000; 38:175-80.

18. Giangaspero F, Chieco P, Lisignoli G, Burger PC. Comparison of cytologic composition with microfluorometric DNA analysis of the glioblastoma multiforme and anaplastic astrocytoma. Cancer. 1987; 60:59-65.

19. Jimenez O, Timms A, Quirke P, McLaughlin JE. Prognosis in malignant glioma: a retrospective study of biopsy specimens by flow cytometry. Neuropathol Appl Neurobiol. 1989; 15:331-338.

20. Perry A, Jenkins RB, O'Fallon JR, Schaefer PL, Kimmel DW, Mahoney MR, Scheithauer BW, Smith SM, Hill EM, Sebo TJ, Levitt R, Krook J, Tschetter LK, et al. Clinicopathologic study of 85 similarly treated patients with anaplastic astrocytic tumors. An analysis of DNA content (ploidy), cellular proliferation, and p53 expression. Cancer. 1999; 86:672-83.

21. Ganju V, Jenkins RB, O'Fallon JR, Scheithauer BW, Ransom DT, Katzmann JA, Kimmel DW. Prognostic factors in gliomas. A multivariate analysis of clinical, pathologic, flow cytometric, cytogenetic, and molecular markers. CANCER-AM CANCER SOC. 1994; 74:920-927.

22. Mørk SJ, Laerum OD. Modal DNA content of human intracranial neoplasms studied by flow cytometry. J Neurosurg. 1980; 53:198-204.

23. El-Rayes BF, Norton CS, Sakr W, Maciorowski Z, Smith D, Pietraszkiewicz H, Del Mar Alonso M, Ensley JF. Cellular DNA content parameters as prognostic indicators in human astrocytomas. J Neurooncol. 2005; 71:85-89.

24. Holland AJ, Cleveland DW. Losing balance: the origin and impact of aneuploidy in cancer. EMBO Rep. 2012; 13:501-14.

25. Kros JM, Waarsenburg N, Hayes DP, Hop WC, van Dekken H. Cytogenetic analysis of gemistocytic cells in gliomas. J Neuropathol Exp Neurol. 2000; 59:679-686.

26. Broniscer A, Laningham FH, Sanders RP, Kun LE, Ellison DW, Gajjar A. Young age may predict a better outcome for children with diffuse pontine glioma. Cancer. 2008; 113:566-72.

27. Casartelli G, Dorcaratto A, Ravetti JL, Sola S, Vitali A, Merlo DF, Frosina G. Survival of high grade glioma patients depends on their age at diagnosis. Cancer Biol Ther. 2009; 8:1719-21.

28. Louis DN, Ohgaki H, Wiestler OD, Cavenee WK, Burger PC, Jouvet A, Scheithauer BW, Kleihues P. The 2007 WHO classification of tumours of the central nervous system. Acta Neuropathol. 2007; 114:97-109.

29. McGirt MJ, Chaichana KL, Attenello FJ, Weingart JD, Than K, Burger PC, Olivi A, Brem H, Quinoñes-Hinojosa A. Extent of surgical resection is independently associated with survival in patients with hemispheric infiltrating lowgrade gliomas. Neurosurgery. 2008; 63:700-7.

30. Li YM, Suki D, Hess K, Sawaya R. The influence of maximum safe resection of glioblastoma on survival in 1229 patients: can we do better than gross-total resection? J Neurosurg. 2016; 124:977-88.

31. Wen PY, Macdonald DR, Reardon DA, Cloughesy TF, Sorensen AG, Galanis E, Degroot J, Wick W, Gilbert MR, Lassman AB, Tsien C, Mikkelsen T, Wong ET, et al. Updated response assessment criteria for high-grade gliomas: response assessment in neuro-oncology working group. J Clin Oncol. 2010; 28:1963-72.

32. Ren X, Cui X, Lin S, Wang J, Jiang Z, Sui D, Li J, Wang Z. Co-deletion of chromosome $1 \mathrm{p} / 19 \mathrm{q}$ and IDH1/2 mutation in glioma subsets of brain tumors in Chinese patients. PLoS One. 2012; 7:e32764.

33. Ambros PF, Ambros IM, and SIOP Europe Neuroblastoma Pathology, Biology, and Bone Marrow Group. Pathology and biology guidelines for resectable and unresectable neuroblastic tumors and bone marrow examination guidelines. Med Pediatr Oncol. 2001; 37:492-504. 